\title{
Capturing the value of green space in urban parks in a sustainable urban planning and design context: pros and cons of hedonic pricing
}

\author{
Gustav Engström $^{1}$ and $\underline{\text { Asa } \text { Gren }^{2}}$
}

\begin{abstract}
Sixty percent of the land that will be urban in 2030 has yet to be built. Contemporary urban development is unsustainable and focus is on building dense, often at the expense of urban green space (UGS), at the same time as our understanding of links between green spaces and human well-being, especially health, is increasing. There is a need to better understand and analyze human well-being qualities of UGS in a planning context. Our aim is to increase this understanding by analyzing the pros and cons of hedonic pricing in this context. Hedonic pricing is commonly used for analyzing benefits associated with UGS to make them more visible and to provide support for urban planning. However, the validity of this approach has been questioned. To increase the accuracy of a hedonic pricing method we incorporate state-of-the-art methods to assess the value of public parks in a case study. Although our results suggest that urban parks indeed have a positive effect on property value and that this effect tends to increase with reduced distance to the parks, the hedonic pricing information is not enough to make well-advised decisions in a sustainable planning context. We thus suggest (1) including and quantifying additional health benefit dimensions and (2) replacing straight-line measures with an axial line step distance measure, to better capture accessibility. To better capture the range of benefits generated by urban parks, irrespective of whether these benefits are enjoyed in direct relation to the park or not, we suggest complementing hedonic pricing via (3) applying an ecosystem service lens, thus also improving the accuracy of trade-off and synergy analysis Also, a sustainable planning approach will benefit from (4) taking the surrounding land use configuration into account for optimizing the different values of urban parks.
\end{abstract}

Key Words: health benefits from urban parks; hedonic pricing; sustainable urban planning; urban ecosystem services, urban green space; valuing urban parks

\section{INTRODUCTION}

The world is experiencing an urbanization trend at a rate unprecedented on the planet and $60 \%$ of the land that will be urban in 2030 has yet to be built (Seto et al. 2012). Although this offers an enormous challenge, it also provides a great opportunity to transform the development of cities toward a more sustainable path (Elmqvist et al. 2013). The current focus in urban planning is mainly on building "smart," i.e., dense, thus saving "nature" outside of the city (see, e.g., James et al. 2013), potentially at the expense of urban green spaces (UGS). Although green spaces have been shown to provide a range of ecosystem services that contribute to better cities (Lovell and Taylor 2013) the potential effects of sacrificing UGS in favor of green areas outside of the city is not well investigated (although see, e.g., Soga et al. 2015). Tangible services like air and water purification, food production, and local climate mitigation have by far received the most attention and research (e.g., MA 2005, TEEB 2010). However, ecosystems provide much more than these tangible services. Access to UGS have also been shown to provide a multitude of health benefits (Hartig and Khan 2016, Hartig et al. 2014) such as stress reduction (Grahn and Stigsdotter 2003, Annerstedt 2011), decrease in heart disease and early death in general (Mitchell and Popham 2008), improved alertness of children with attention deficit disorder (Taylor and Kuo 2009), and increased physical activity (Kaczynski and Henderson 2007). UGS have even been shown to influence social cohesion by, e.g., providing a meeting place for users to develop and maintain neighborhood ties (Kazmierczak 2013). Similarly, psychological benefits have also been shown to exist with access to open water (Nutsford et al. 2016).
All of these benefits are connected to our natural capital and there is thus a need to assess the value of that capital if we are to make good decisions on how UGS can be better promoted as a part of public policy (Helm 2015). The economic valuation of ecosystem services in general has gained great interest over the last decade (see, e.g., Nelson et al. 2009, TEEB 2010), also with a specific focus on urban areas (TEEB 2011). Valuation of ecosystem services involves dealing with multiple, and often conflicting, value dimensions (Martín-López et al. 2014) and can entail the exploration of a range of value domains, including biophysical, monetary, socio-cultural, health, and insurance values (GómezBaggethun et al. 2013). To address multiple ecosystem services it is often necessary to use a combination of valuation methods (see, e.g., Boyer and Polasky 2004, Costanza et al. 2006, Escobedo et al. 2011). Hedonic pricing, an economic valuation method designed to, e.g., capture the value of UGS in terms of their contribution to the market value of housing property, is commonly used for analyzing the benefits associated with UGS in order to make them more visible and to provide support for urban planning in both America and Europe (see, e.g., Tyrväinen 1997, Tyrväinen and Miettinen 2000, Kolbe and Wüstemann 2015), as well as in Asia (see, e.g., Kong et al. 2007) and Australia (Hatton MacDonald et al. 2010, Mahmoudi et al. 2013) . In this paper we focus on urban parks as the UGS unit of study. The hedonic pricing method (HPM) belongs to the revealed preferences methods, i.e., it tries to infer the value of a nonmarket good by observing the actual behavior of individuals on related markets (see, e.g., Alriksson and Öberg 2008). However, the validity of this approach has been questioned because of the common existence of spatial autocorrelation when estimating

${ }^{1}$ The Beijer Institute of Ecological Economics and Global Economic Dynamics and the Biosphere, The Royal Swedish Academy of Sciences, ${ }^{2}$ The Beijer Institute of Ecological Economics, The Royal Swedish Academy of Sciences 
these types of models (Anselin and Arribas-Bel 2013). The reason for this is due to downward biased estimates of standard errors implying that we may perceive that there is an effect of UGS when there actually is none (see Anselin and Arribas-Bel 2013). Also, because of the multitude and complexity of ecosystem service generation (Raudsepp-Hearne and Peterson 2016) there is reason to question the validity of the HPM in a sustainable urban planning and design context by questioning the rationality of one of the assumptions behind the HPM, namely that individuals are able to perceive environmental quality changes, that these changes affect future net benefit streams of a property, and that it thus can be assumed that people therefore are willing to pay for environmental quality changes (Treweek 1999).

In this paper we thus (i) address the validity of a hedonic pricing approach, using empirical data from a case study in the municipality of Malmö, Sweden. We build on traditional methods from hedonic pricing and extend them to also incorporate the latest state-of-the-art methods used to control for spatial autocorrelation. Much of the previous literature using hedonic pricing methods have done little to control for this problem and typically resorted to fixed effects estimation (see, e.g., Kuminoff et al. 2010). In the hedonic pricing context the fixed effects usually refer to specific spatial entities. Anselin and Arribas-Bel (2013) have however questioned the validity of spatial fixed effects and concluded that unless the spatial correlation takes on a groupwise structure (meaning that only observations within and not across spatial units are correlated), there is no reason why spatial fixed effects should be sufficient to avoid the statistical inference problems (biased standard errors) resulting from spatial correlation. This brings much of previous results in the literature on the connection between green space and property values, using hedonic pricing methods, into question and we cannot be sure that earlier results in the literature would still hold when spatial autocorrelation is properly accounted for. We then (ii) discuss the pros and cons of the validated HPM in a sustainable urban planning and design context focusing on human health benefits because these types of benefits, sometimes referred to as being part of cultural ecosystem services, have been shown to be of great importance, especially in an urban context (Gómez-Baggethun et al. 2013, Andersson et al. 2015).

\section{METHODS}

We have tried to be as robust as the state-of-the-art methods allows us to be and analyzed the data using both spatial fixed effects but also spatial econometric methods as well as combinations of the two. The hedonic pricing regressions are run using a large data set on housing sales with a wide variety of characteristics including neighborhood specific attributes such as median income levels and ethnical segregation. Apart from the standard methods we also make use of heat maps to provide a more indepth view of which areas in space sell at a higher or lower value. Overlaying such a map with a map of urban parks can provide evidence of which parks increase property values and which do so to a lesser degree or not at all. This information could thus be of substantial value to urban landscape planners.

\section{Study area and data}

The data used in this paper consists of real estate transactions for both ownership apartments in cooperative housing associations and private housing, in the municipality of Malmö and covers the period October 2010 to April 2015. Malmö municipality has a land area of $158.39 \mathrm{~km}^{2}$ and a population size of around 300,000 and is located in the south of Sweden, with easy access to Copenhagen via a bridge and tunnel connecting Sweden to Denmark. The population has been growing at an average yearly rate of approximately $1.3 \%$ since 1990 . Although population increase has been substantial, Malmö has had a relatively weak economic development (including low growth in job opportunities) compared with the rest of Sweden. Income segregation has also increased; starting at an initially low level, it increased during the economic downturn in Sweden (1992-1994), and then remained relatively stable at the new higher level (see Andersson and Hedman 2016). Along with the rest of Sweden the ethnic population composition has also changed substantially. The percentage of foreign born in the working population of Malmö has increased from $14 \%$ to almost $26 \%$ while the percentage of foreign born from non-Western countries has grown from $3 \%$ to $11 \%$, a trend similar to the overarching trend in Sweden (Andersson and Hedman 2016). Also, in the context of space, Malmö is a very compact city, much more so than, e.g., Stockholm (the capital of Sweden) and the core consists of areas with distinctive suburban features with a high proportion of immigrants, high unemployment rates, and poverty (Thor 2016).

The transaction data includes information on, e.g., sales price, list price, contract date, living area, floor number, monthly fees, number of rooms, and two types of geographical information: address and county, and latitude and longitude. The data set was attained from Svensk Mäklarstatistik (Swedish real estate statistics), which, together with Statistics Sweden, collects the data from the majority of all real estate agencies in Sweden.

Because data entry, on part of the real estate agents, obviously is prone to human error, we carried out a number of data cuts to minimize the likelihood of errors in our data set. First, we removed all transactions where the data was either missing or extreme. For the final sale and list price this involved removing all transactions with a sale or list price below 10,000 Swedish Crowns (SEK; $\approx$ US\$1400) or above $10,000,000$ SEK, which we considered to be very unlikely. We also removed all observations where the provided living area was either zero, negative, or missing, or where the monthly fee was negative or missing. Finally, we also checked for internal inconsistencies in the geographical information provided by the real estate agents, i.e., we wanted to test whether the address information entered by the real estate agents also matched the coordinates they provided, for each respective transaction. This was done by geocoding the entire data set, which is a process of finding the associated geographical coordinates for some geographic data provided in another format. This was done by processing the address and county specific information for each transaction using Google's geocoding API, which provided us with a new set of geographical coordinates based on this information. Using GIS software we then measured the Euclidian distance between the coordinates returned by the Google's geocoding API and the transaction coordinates provided by the real estate agents and removed all observations with large discrepancies (distances) in the geographical information provided (the cut-off was made at 50 meters). For the remaining transactions, GIS software was then used to place them in their corresponding census tract based on these geographical coordinates. Finally, we decided to exclude all observations with 
Fig. 1. Map of Malmö municipality including parks, census tracts, and observations. See legend for details.

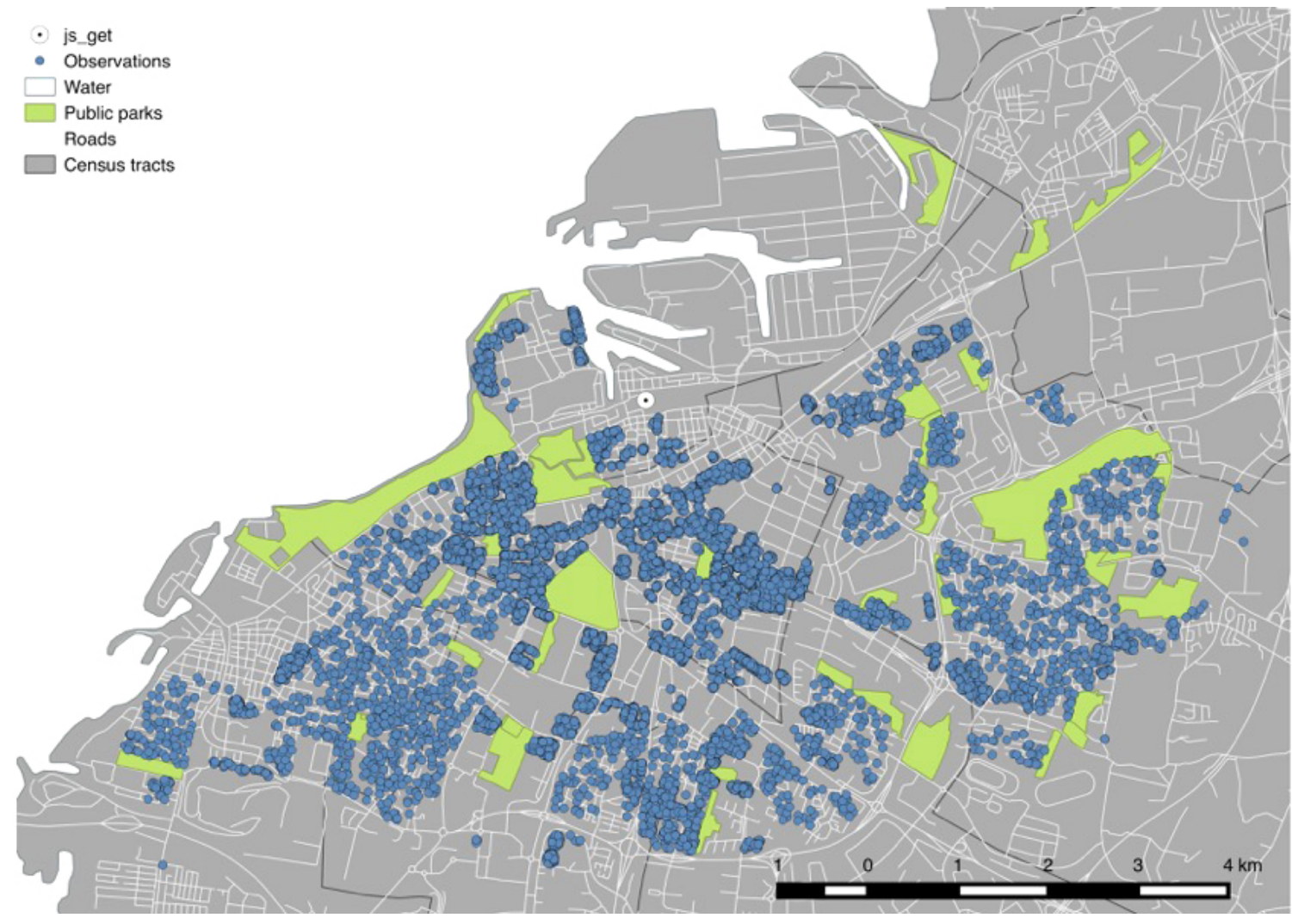

distances more than 1000 meters from the closest park. One could clearly argue that the cut-off should be made larger/smaller. At some distance, however, the impact a park has on property values is likely to become too small to be distinguishable from other amenities in the data. Interpretation of our estimates derived below should thus be made in light of this cut-off level. After making these cuts the resulting number of observations where 16,655 .

Data on parks where obtained as a GIS layer provided by Malmö municipality. This data included park area and location and thus treated all parks as equal. From this dataset we excluded small parks with a size below 40,000 square meters. Similar to the choice of cut-off distance one could argue that even smaller sized parks and green patches should be included because there exists substantial evidence they also provide value to residents (Whyte 2001). However, because larger sized parks provide a larger variety of recreational uses, they should also exert a stronger effect on housing prices in their vicinity and thus increase the potential for us to distinguish such effects from all other potential neighborhood amenities. In any case it is important that the results below are interpreted only for parks greater than 40,000 square meters. Other variables that may be of importance for explaining property prices include data on incomes and ethnic diversity. Average population data for geographical units of 250 by 250 meters was attained from Lantmäteriet. From this data we constructed two variables: (i) median yearly incomes for families 20 years and older and (ii) share of population with non-European birthplace. Recent media cover indicates that these variables may be negatively correlated (that is high median incomes entail a lower share of population with non-European birthplace). We expect these variables to impact on property prices, increasing with median incomes and decreasing with higher share of population with non-European birthplace.

Figure 1 depicts the study area. The dark grey surrounded by black lines are the administrative units, the white lines represent a road map (for presentation purposes only) and the green areas denote the parks included in our analysis. The white circle with a dot in the center depicts the location of the central station. The other dots denote observations.

Descriptive statistics for all of the variables in our dataset can be found in Table 1. The average contract price for a sale during our period was around 1.6 million SEK. The average distance to parks was around 400 meters. Apart from the variables in the list below we also include time dummies for each quarter of the year for all regressions in our analysis. In total this involves 15 dummies for the entire period.

\section{The econometric model}

Hedonic pricing models are widely used for assessing economic values associated with environmental amenities. The idea, based on the work of Rosen (1974), is that the price of a good can be decomposed into the marginal implicit prices of each separate characteristics of that good, which thus equals the buyer's marginal willingness to pay for that specific attribute. In the 
Table 1. Summary statistics for final sample.

\begin{tabular}{|c|c|c|c|c|}
\hline & mean & std & $\min$ & $\max$ \\
\hline contract_price & 1578906 & 1134604 & 14000 & 9750000 \\
\hline living_area & 77 & 35 & 11 & 414 \\
\hline monthly_fee & 3265 & 2124 & 0 & 42334 \\
\hline number_of_rooms & 3 & 1 & 1 & 12 \\
\hline plot_area & 73 & 239 & 0 & 12834 \\
\hline building_storeys & 4 & 3 & 0 & 19 \\
\hline apartment_floor & 2 & 2 & 0 & 19 \\
\hline park_dist & 407 & 253 & 0 & 1000 \\
\hline water_dist & 3028 & 2135 & 10 & 11414 \\
\hline central_dist & 3063 & 1750 & 125 & 10464 \\
\hline build_year & 1954 & 25 & 1800 & 2014 \\
\hline median_income & 298317 & 121342 & 0 & 1309302 \\
\hline popshare_non_euro & 0.16 & 0.11 & 0.00 & 0.61 \\
\hline
\end{tabular}

housing market an apartment can thus be decomposed into its constituents, for instance, number of rooms, bathrooms, square meters, apartment floor number, etc. All of these characteristics make up different contributions to the final sale price of the apartment. On top of these interior characteristics, neighborhood characteristics also contribute to the final prices. Examples include, access to public transportation, median income levels, distance to recreational areas such as parks.

We use data on apartment sales prices along with other observable characteristics of apartments to estimate the marginal willingness to pay for living close to a park. This is done by using a multiple regression model with apartment price as the dependent variable and various characteristics as explanatory variables. Theory has little to say about the form of the hedonic pricing function. However, from graphical inspection of our variables we can conclude that at the minimum the final price variable in our data set benefits from a log transformation, which generates a closer fit to the normal distribution. As in much of the hedonic pricing literature we thus use both $\log -\log$ forms and semi-log forms for our pricing function, which implies that parameters may be interpreted as either a percentage change in the explanatory variable leads to a percentage change in the dependent variables $(\log -\log )$ or one unit change in the explanatory variable can be interpreted as a percentage change in the price of the apartment (semi-log form). Previous studies have also found that a $\log$ transformation of distance variables generally perform better than simple linear functional forms because the $\log$ transformation captures the declining effect of these distance variables (see Bin and Polasky 2004, Mahan et al. 2000). Following these studies we thus used log transformations for all distancerelated variables.

It should be noted that apart from considerations regarding the functional form for the hedonic function the estimation of a hedonic price function poses a number of other econometric problems. Perhaps the most severe of these problems is the endogeneity problem that arises because of the fact that property values also determine residential development. In other words, unobserved variables that determine home values will likely be correlated with our variable of interest, i.e., the distance to parks. This gives rise to what is commonly referred to as omitted variable bias, which as the name suggests biases our estimates of interest.
There are several ways in which one may deal with this bias. Among the most popular ways of dealing with this problem is by using either instrumental variables or quasi-experimental methods (such as difference-in-difference). These methods, however, require either good instruments, which are hard to come by, or exogenous events in the variable of interest, which also is unlikely to be observable when analyzing the value of public parks because there is usually little variation in this variable over time. Because these two methods are rarely applicable, other ways of dealing with omitted variable bias has been developed and adopted to the hedonic model.

The first, and perhaps the most simple, is the use of "fixed effects" applied to some administrative unit such as census tracts. The fixed effects model (commonly used with panel data) is simple because it can be easily estimated using ordinary least square including dummy variables for each administrative unit, which indicates whether a specific observation belongs to that unit or not. The idea is that these dummy variables will absorb the price effect of spatially clustered omitted variables.

The second method incorporates spatial dependence directly into a regression specification and is usually called spatial econometrics. Examples are the spatial lag and the spatial error model (Anselin 1988). In all cases this involves the prespecification of a spatial weight matrix, which can take on many forms such as nearest neighbor or inverse distance.

Kuminoff et al. (2010) performed Monte Carlo simulations to evaluate the performance of different econometric techniques for controlling for omitted variable bias due to spatial auto correlation in hedonic pricing. They found that adding fixed effects to the model reduced the bias by $7.3 \%$ while the spatial error model only had a marginal improvement over a model with no spatial controls and that the spatial lag model actually performed worse when using a "nearest neighbor" specification for the spatial weight matrix. They conclude that in, e.g., a metropolitan area with a large number of census tracts, spatial fixed effects could offer a flexible way of absorbing the irregular concentration of omitted variables.

Anselin and Arribas-Bel (2013) have investigated this conjecture more closely. They point to a number of problems with fixed effect estimation that may result in spatially dependent or 
heteroskedastic error terms. For example, fixed effects estimation assume that there is no within group heterogeneity and there is in most cases no reason why the administrative units chosen in most studies should be homogenous, which thus implies that the size of these units may matter. In general, they find that except for the special case in which the spatial correlation takes on a group-wise structure, there is no reason why spatial fixed effects should correct for the presence of spatial correlation. Further, unless there is a strong theoretical or practical reason why a distance decay relationship between observations should be ruled out, the use of spatial fixed effects will not be sufficient to correct for the presence of spatial correlation.

Because the present paper is a purely empirical application and we make no attempt to solve the dispute on which method best addresses the omitted variable bias caused by spatially dependent observations, we thus present results for both a fixed effects estimation and estimation guided by recent advances in spatial econometrics. The models we consider are the following:

$$
\begin{gathered}
\ln \left(P_{g t}\right)=\kappa_{t}+\alpha X_{g t}+\beta Z_{g t}+\gamma_{g}+\epsilon_{g t} \\
\ln \left(P_{t}\right)=\kappa_{t}+\alpha X_{t}+\beta Z_{t}+\rho W \ln \left(P_{t}\right)+\epsilon_{t} \\
\ln \left(P_{t}\right)=\kappa_{t}+\alpha X_{t}+\beta Z_{t}+\epsilon_{t}, \quad \epsilon_{t}=\lambda W \epsilon_{t}+u_{t}
\end{gathered}
$$

where $g$ denotes census tract (group); $t$ denotes time; $P$ denotes $N \times 1$ vector of final sale price; $\mathrm{X}_{t}$ is a $N \times k$ vector of home structural characteristics; $Z_{t}$ a $N \times l$ vector of neighborhood characteristics including distance to parks; $\alpha, \beta$ are the parameter vectors to be estimated; $\kappa_{t}$ is a vector of dummy variable which capture seasonal and time trend variations; $\varepsilon$ is a $N \times 1$ vector of error terms. The first equation is the fixed effect model where $\gamma_{g}$ denotes the census tract fixed effects. The second and third equations are the spatial econometric lag and error forms, both of which must include a prespecified $N \times N$ spatial weight matrix $W$ and the estimation of parameters $\rho$ and $\lambda$, respectively. The spatial lag form (2) involves lagged dependent variables, which in our case are the logged final prices and can be estimated using spatial two stage least squares (Anselin 1988, Kelejian and Prucha 1998). The spatial-error form (3) can be estimated using the generalized moments estimator of Kelejian and Prucha (1998), Drukker et al. (2013), Arraiz et al. (2010). The spatial lag and error form can also be estimated jointly if there is evidence of both types of spatial auto correlation.

\section{Testing for and analyzing the effect of autocorrelation}

To determine, among other things, whether spatial correlation is of concern here, we started by running some diagnostic tests. The estimations were done using the PySal package for Python. We tackled the potential problem of heteroskedasticity by using a robust VC matrix following White's (1980) procedure in our estimations

At this point, we were ready to consider the issue of spatial dependence and explicitly incorporate space into the model. For the spatial econometric analysis we had to make an assumption regarding the form of the spatial weight matrix. Here we followed Anselin and Arribas-Bel (2013) and used a k-nearest neighbor criterion with a total of 20 neighbors. As in Anselin et al. (1996) we then tested for spatial autocorrelation using both robust and nonrobust Lagrange Multiplier tests for lag and error specifications.

The analysis we undertook based on the econometric model was twofold. First, we conducted a standard regression analysis to get quantitative measures on how changes in our distance variable of interest affected the contract price. This was the standard method used in the literature trying to connect property values to green space. Second, we produced heat maps with the intension of giving a more detailed picture of what the spatial correlation looks like. Which areas are hot and which are not? The aim here was thus to produce some visual guidelines that can help get a preliminary idea of what the correlation between distance to parks and house prices might look like after controlling for the different characteristics presented in Table 1 .

\section{RESULTS AND DISCUSSION}

\section{General regression results}

The diagnostic tests, using the PySal package from Python, revealed that the data is not normally distributed and exhibits heteroskedasticity, which is expected with data of this type. The assumption of normality of the residuals is important in linear regression when the size of your sample is limited. However, as the sample size grows, this is less relevant because of the central limit theorem. Because we have a large sample of over 15,000 observations, we will thus assume we can rely on the central limit theorem. The problem of heteroskedasticity is more severe and was handled by using a robust VC matrix following White's (1980) procedure in our estimations. When testing for spatial autocorrelation using both robust and nonrobust Lagrange Multiplier tests for lag and error specifications all tests revealed severe presence of spatial autocorrelation.

\section{Results from running the different econometric models}

Table 2 shows the results of four different models, based on the three models described earlier, varying in the way they control for spatial auto correlation. We start by looking at the first column, which depicts the results when not controlling for any spatial auto correlation. This model can thus be seen as a baseline for comparison representing the best possible functional model accounting only for heteroskedasticity using White's (1980) robust standard errors but not for spatial auto correlation. From this model we see that all variables come out highly significant at the $1 \%$ level. Because of the lack of control for spatial auto correlation, we know, however, that it is fairly likely that we are making a Type one error, i.e., rejecting the null when it is in fact true. Disregarding this at the moment, we can, however, see that the parameter estimates have intuitive signs. For example, an increase of $1 \%$ in the living area of a house increases the final sale price by approximately $0.75 \%$. Also note that, the number of rooms, the floor level (for apartments), and plot area (houses) all increase the final sales price, which is also intuitive. Considering the neighborhood variables this also comes out intuitively. Distances to the city center and waterfront increase the sales price, which is in line with previous findings such as Nutsford et al. (2016). This also holds for median income areas, i.e., areas with a higher median income are associated with higher final sales prices. Further, it is also interesting to see the effect of the variable share of population with non-European birthplace. As can be seen, this variable is negatively correlated with final sales price 
Table 2. Estimation results for the hedonic price functions for the four different models (nonspatial, fixed effects, GM Combo, and GM Combo with fixed effects, see text for model details). Rows contain parameter estimates and their corresponding standard errors in parenthesis. Last row contains the R2 value for each model.

\begin{tabular}{|c|c|c|c|c|}
\hline & nonspat & fixed-effects & GM Combo & GM Combo (fe) \\
\hline CONSTANT & $\begin{array}{c}391.57 * * * \\
(62.52)\end{array}$ & $\begin{array}{c}444.13^{* * *} \\
(64.16)\end{array}$ & $\begin{array}{c}153.31 * * * \\
(58.67)\end{array}$ & $\begin{array}{c}164.06^{* * * *} \\
(58.76)\end{array}$ \\
\hline living_area & $\begin{array}{c}0.6812^{* * *} \\
(0.0178)\end{array}$ & $\begin{array}{c}0.6807^{* * *} * \\
(0.0181)\end{array}$ & $\begin{array}{c}0.6357^{* * *} \\
(0.0186)\end{array}$ & $\begin{array}{c}0.6361 * * * \\
(0.0186)\end{array}$ \\
\hline monthly_fee & $\begin{array}{c}-0.0176 * * * \\
(0.0022)\end{array}$ & $\begin{array}{c}-0.0181^{* * *} \\
(0.0021)\end{array}$ & $\begin{array}{c}-0.0057^{* * *} \\
(0.002)\end{array}$ & $\begin{array}{c}-0.0058 * * * \\
(0.002)\end{array}$ \\
\hline rooms & $\begin{array}{c}0.2563^{* * *} \\
(0.0208)\end{array}$ & $\begin{array}{c}0.2566^{* * *} * \\
(0.0209)\end{array}$ & $\begin{array}{c}0.2681 * * * \\
(0.0211)\end{array}$ & $\begin{array}{c}0.268 * * * \\
(0.0211)\end{array}$ \\
\hline floor & $\begin{array}{c}0.0238 * * * \\
(0.0036)\end{array}$ & $\begin{array}{c}0.0197 * * * \\
(0.0036)\end{array}$ & $\begin{array}{c}0.0263 * * * * \\
(0.0031)\end{array}$ & $\begin{array}{c}0.0261 * * * \\
(0.0031)\end{array}$ \\
\hline park_dist & $\begin{array}{c}-0.0156 * * * \\
(0.0024)\end{array}$ & $\begin{array}{c}-0.0192 * * * \\
(0.0023)\end{array}$ & $\begin{array}{c}-0.0116^{*} \\
(0.0059)\end{array}$ & $\begin{array}{c}-0.0133 * * \\
(0.0058)\end{array}$ \\
\hline water_dist & $\begin{array}{c}-0.1433 * * * \\
(0.0038)\end{array}$ & $\begin{array}{c}-0.1175^{* * * *} \\
(0.0048)\end{array}$ & $\begin{array}{c}-0.1267^{* * *} \\
(0.014)\end{array}$ & $\begin{array}{c}-0.1112^{* * * *} \\
(0.015)\end{array}$ \\
\hline plot_area & $\begin{array}{c}0.0698^{* * *} \\
(0.003)\end{array}$ & $\begin{array}{c}0.0708^{* * *} \\
(0.003)\end{array}$ & $\begin{array}{c}0.0771 * * * \\
(0.0034)\end{array}$ & $\begin{array}{c}0.0772 * * * \\
(0.0034)\end{array}$ \\
\hline park_area & $\begin{array}{c}0.0135^{* * *} \\
(0.0019)\end{array}$ & $\begin{array}{c}0.0216^{* * *} \\
(0.002)\end{array}$ & & \\
\hline central_dist & $\begin{array}{c}-0.2901 * * * \\
(0.0066)\end{array}$ & $\begin{array}{c}-0.2748^{* * *} \\
(0.0073)\end{array}$ & $\begin{array}{c}-0.2852^{* * *} \\
(0.016)\end{array}$ & $\begin{array}{c}-0.27 * * * \\
(0.0182)\end{array}$ \\
\hline build_year & $\begin{array}{c}-1048.1 * * * \\
(173.3)\end{array}$ & $\begin{array}{c}-1196.6^{* * *} \\
(177.8)\end{array}$ & $\begin{array}{c}-393.7 * * \\
(162.79)\end{array}$ & $\begin{array}{c}-424.32 * * * \\
(163.03)\end{array}$ \\
\hline build_year_sq & $\begin{array}{c}503.62^{* * *} \\
(83.26)\end{array}$ & $\begin{array}{c}575.74 * * * \\
(85.46)\end{array}$ & $\begin{array}{c}189.3^{* *} \\
(78.43)\end{array}$ & $\begin{array}{c}204.14 * * * \\
(78.54)\end{array}$ \\
\hline median_income & $\begin{array}{c}0.0888^{* * *} * \\
(0.013)\end{array}$ & $\begin{array}{c}0.0966^{* * *} \\
(0.0156)\end{array}$ & & \\
\hline popshare_non_euro & $\begin{array}{c}-1.5076^{* * *} \\
(0.0385)\end{array}$ & $\begin{array}{c}-1.4323 * * * \\
(0.0421)\end{array}$ & $\begin{array}{c}-0.6607 * * * \\
(0.0622)\end{array}$ & $\begin{array}{c}-0.6464 * * * \\
(0.0617)\end{array}$ \\
\hline lambda & & & $\begin{array}{c}0.8025^{* * *} \\
(0.0109)\end{array}$ & $\begin{array}{c}0.7941 * * * \\
(0.0114)\end{array}$ \\
\hline rho & & & $\begin{array}{c}-0.0482^{* * *} \\
(0.0077)\end{array}$ & $\begin{array}{c}-0.0482 * * * \\
(0.0077)\end{array}$ \\
\hline R2 & 0.87235 & 0.87629 & 0.88664 & 0.88927 \\
\hline
\end{tabular}

$*(\mathrm{p}<0.05),{ }^{* *}(\mathrm{p}<0.01),{ }^{* * *}(\mathrm{p}<0.001)$

Robust standard errors in parentheses

such that areas with a high share of the population born outside Europe have lower property values. The correlation with median incomes thus suggests the population in these areas also have lower incomes indicating a significant degree of cultural and income segregation in Malmö.

In particular we note that as the distance to parks increases this impacts negatively on the price. Also, the park area estimate tells us that the larger the parks the higher the value of being close to it.

As already pointed out, the most straightforward and common way of addressing the problem of spatial auto correlation is the fixed-effects model. Estimates for this model are found in the second column of Table 2. Here, we have applied fixed effects to fairly large census tracts, which can be seen from Figure 1. Because of the large size of these census tracts, it is thus likely that there still remains considerable spatial correlation within each unit. However, from Table 1 we can see the higher estimate tells us that at the least the explanatory power has increased somewhat, which we have also confirmed from the adjusted estimates (not presented here).
Next, we turn to the spatial econometric model. The Lagrange tests for spatial autocorrelation did not give us any indication whether the error model (3) or lag model (2) is preferable. We thus proceeded by testing both spatial error models and lag models to see whether the lag and error estimates were significant for both types of correlation. For the spatial lag model we used a particular case of the traditional Instrumental Variables (IV) approach, in which the endogeneity of the spatial lag of the variable is dealt with by using instruments (see Kelejian and Prucha 1998). For error model we used an estimation procedure proposed by Arraiz et al. (2010), which allows estimation of error models that are consistent to the presence of heteroskedasticity. The results from these estimations lead us to conclude that both types of spatial autocorrelation seem to be present. We thus turn to a combined model, which captures both kinds of autocorrelation based on the work of Kelejian and Prucha $(1998,1999)$.

Column 3 "GM Combo" and 4 "GM Combo (fe)" of Table 2 show the results for the combined model controlling for both spatial correlation, using both a lagged dependent and error specification, which is estimated using a generalized method of moments estimator. The difference between the two is that column 
4 includes the spatial fixed effects used in column 2. As can be seen the estimation results are substantially different compared with the previous two columns. The R-values have increased and we are now explaining approximately $89 \%$ of the variation in the data. The variables park area and median income have, however, now turned insignificant and have thus been excluded from the regression. Further the Table reports estimates for the coefficients of the spatial weight matrix where lambda is the coefficient belonging to the lagged dependent variable and rho belongs to the error form. As can be seen, these estimates are both highly significant indicating that our combined model is the better choice for modeling spatial autocorrelation. Turning to our estimate of interest, the distance to parks, we now see that the estimate is not as strong as before and has gone from significance on the $1 \%$ level to the 10 and $5 \%$ level, respectively.

Overall, after having considered both spatial fixed effects, the lagged dependent variable, and error form, the model results point to a significant effect of distance to parks on property values. Based on these results for the city of Malmö the general conclusion is that a decrease in the distance to parks of 100 meters would increase the final sale price of a house in our dataset by a minimum of $1 \%$. To put the number in perspective, consider the following thought experiment. Imagine that a single park of average size gets paved over to make room for some other usage with no amenity value to citizens in its vicinity. Consider the individuals living on the border of a circle surrounding the former park. Assume that after paving, these individuals now instead have 200 meters to the nearest park. This implies that the value of their property, interpreted through the lens of our estimation results, has decreased by $1 \%$. What is then the total property value lost? If we take the mean values for the contract price at (1.6 million.), living area $\left(77 \mathrm{~m}^{2}\right)$, and building floors (4) from our summary statistics in Table 1 and assume that buildings are located at 50 meters apart we can then calculate a hypothetical measure of total value for houses located along the line of a circle (with radius $100 \mathrm{~m}$ ) around the paved park (hence having a circumference of $628 \mathrm{~m}$ ). This allows us to squeeze in approximately five buildings along the circumference with a total value of 32 million $(1.6 * 5 * 4)$. This would thus imply that the total property value lost amounts to 0.32 million for these properties only. To this figure you would then have to add the value lost to all buildings within the circumference, which would be higher because the distance to their closest park is even longer than those properties located on the circumference. In sum substantial values are likely lost because of development, which is typically not accounted for in public planning.

\section{Heat maps}

We plotted two heat maps based on the residuals from an equal number of regressions. By "heat" we will be referring to how property values vary, based on the surrounding amenities. The idea here is that by running reduced regressions we can get a visual idea of which areas are hot and which are not when it comes to specific variables. The heat maps are constructed using an inverse distance type interpolation between the residuals of observations, which result from regression analysis. We start with a simple regression analysis featuring only house specific attributes to provide a comparison. The results are depicted in the first map (Fig. 2) that shows the residuals from a regression analysis of the variables, living area, monthly fee, plot area, floor number, and building stores together with time dummies on the contract price. This resulted in an R-value of 0.61 implying that we are already explaining around $61 \%$ of the variation in final prices. The interpretation of the resulting residuals is the deviation from the average price after controlling for all housing specific attributes. Alternatively we can also view these residuals as a representation of neighborhood values, i.e., all neighborhood specific characteristics affecting final sale prices.

The colors of the heat-map range from blue to red indicating whether properties in this area typically sell at a lower value than average (blue) or higher than average value (red). The magnitude of the differences is indicated in the legend. Taking the expectation of these values we can get an idea of the percentage difference in price. For example, the most red area sells at approximately $17 \%$ $(=\exp [0.158])$ higher value relative to the city mean. From the map we can thus see that the most attractive neighborhoods are located in the vicinity of the central station and the waterfront. From this simple regression it is so far hard to see any correlation between the parks and property values.

In the second regression analysis we include neighborhood specific attributes. By this we mean that we include all variables from Table 1 with the exception of park area and park distance. We are thus controlling for several neighborhood characteristics such as median income, share of non-European population, distance to city center, and waterfront. However, by leaving out the variables park distance and area from our regression, this hopefully reveals more clearly whether the vicinity to a specific park is associated with a higher property value. The residuals from this regression are depicted on the map in Figure 3. As can be seen the resulting map shows a lot more color variation than the previous map. This map thus gives us a better idea with regard to which parks are more and which are less valued on the housing market. Here we see that in particular the area around the triangular park (Pildammsparken) is strongly red colored indicating that this is a popular area on the housing market. From the legend, we find that these areas sell at approximately $3 \%$ higher value relative to the city mean. On the opposite end, westnorthwest from Pildammsparken, we have the area of Kirseberg where these smaller sized parks do little for the housing values in its vicinity. Although, we do not control for it explicitly in our model we believe that this diversion, apart from quantitative factors such as size, is likely due to the qualitative differences among the different parks. Pildammsparken, for example, is a well-known recreational park in Malmö and a popular area for picnicking, running, or exercise in general.

To sum up, the value of heat maps in the way we portrayed them here is that they can tell us something more specific about the spatial distribution of property values as opposed to the more general regression analysis that is the most common method used in the literature. For an overview of common regression methods see Kuminoff et al. (2010).

Pros and cons of hedonic pricing: unpacking the green in urban parks in a sustainable urban planning and design context

Our results from the hedonic pricing exercise, when correcting more effectively for autocorrelation, still show that people have a willingness to pay for living next to a park, expressed via the price of properties. However, the results from the hedonic pricing exercise do not tell us what type of and how many benefits that 
Fig. 2. Malmö heat map based on residuals extracted from a regression featuring only housing specific characteristics (excluding all neighborhood attributes). Red (blue) areas indicate that properties in that region typically sell at a relatively higher (lower) price. The legend indicates the magnitude of the difference. Taking the exponential of these values we get the percentage relative difference in selling price for the different areas.

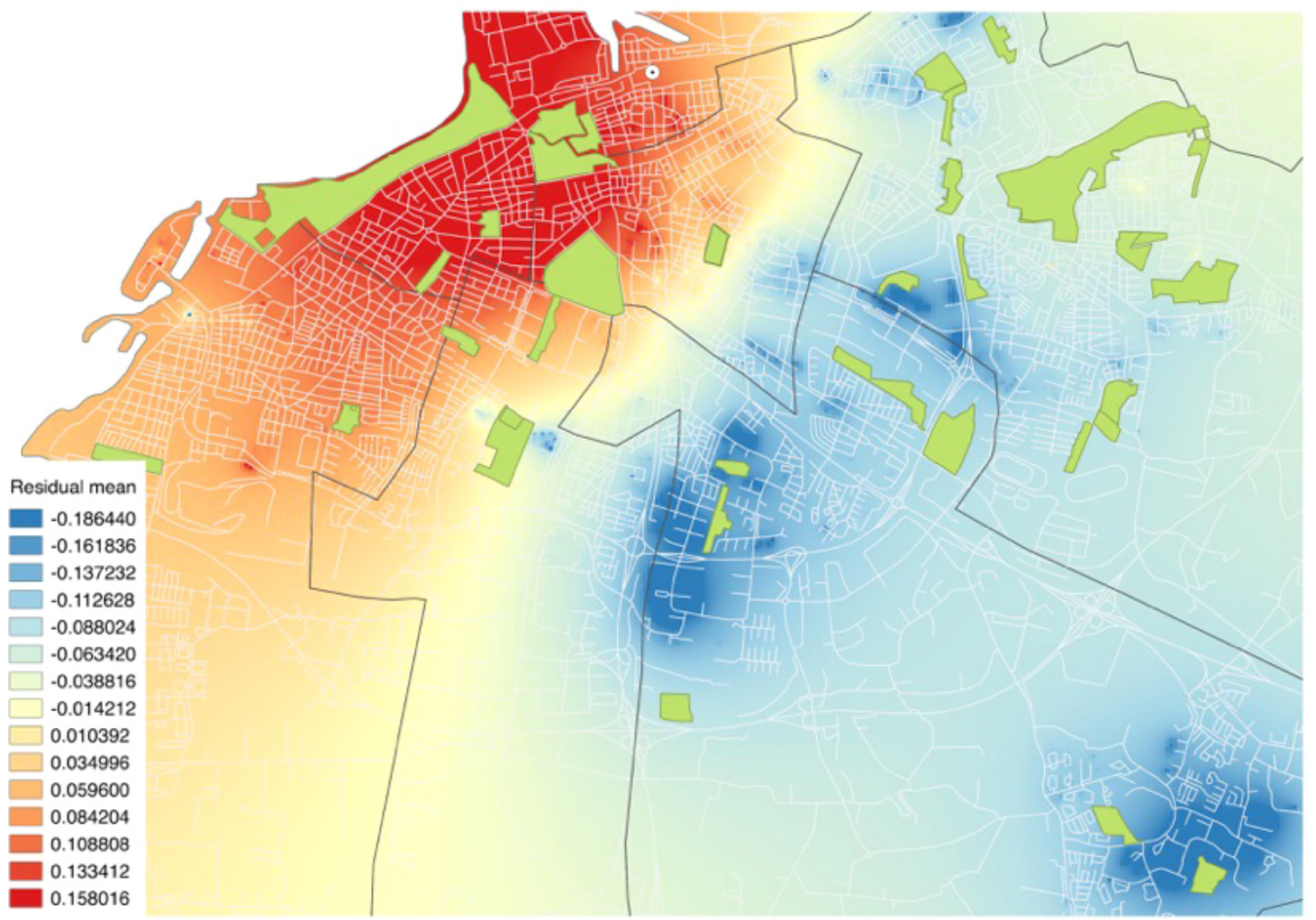

people value in connection to different urban parks, only that people value living close to urban parks. This lack of information makes it difficult to design plans for how to maintain, add, and/ or enhance different benefits that people draw from different parks, i.e., to do sustainable planning and design. There is thus a need to "unpack" the urban green in this context.

\section{Accounting for size of urban parks}

Urban parks can deliver a multitude of health/well-being benefits to people. However, all parks do not deliver all or the same collection of benefits (see, e.g., Grahn and Stigsdotter 2010). To illustrate the importance of identifying which types of benefits can be potentially generated within different types of urban parks, i.e., unpacking the urban green, and to exemplify how this may be done, we use Grahn and Stigsdotter's (2010) classification of health benefits in urban parks or urban open spaces into eight dimensions (Nature, Culture, Prospect, Social, Space, Rich in species, Refuge, and Serene) as a basis for our discussion. Their results show that "Serene" was the most preferred dimension, followed by "Space" and "Nature." "Serene" is described as an urban park or urban open space that is silent and calm; no bikes or mopeds; one can spend time there without coming into contact with too many people; there are plenty of people and movements; it is possible to watch other people being active, playing, practicing sports, etc.; the area is clean and well maintained; there is no traffic noise from the surroundings; it feels safe spending time there (Grahn and Stigsdotter 2010). "Space" is described as an urban park or urban open space experienced as spacious and free; it is possible to find areas not crossed by roads and paths; there are lots of trees; it is possible to find places where a company of several persons can gather; there are places sheltered from the wind; there are sunny and shady places (Grahn and Stigsdotter 2010). "Nature" is described as an urban park or open space that has a natural, wild, hilly, and untouched quality; it feels safe; the visitor can light a fire; you do not risk bumping in to other people too frequently (Grahn and Stigsdotter 2010). All these three dimensions put focus on size because they all require comparatively large areas of urban green to fulfill their purpose, e.g., enough space to not frequently encounter other people, or to avoid experiencing disturbance from traffic etc., hence supporting the focus of size of urban parks as a parameter of great importance. This is also confirmed by our results, e.g., in the context of the high value of the areas around the Pildamms park (Pildammsparken; see Fig. 3). As long as the result from the HPM is not to be used in a planning and design context, the simple correlation between park size per se and value is not a problem. However, if we, through urban planning and design, are to manage and develop the generation of health benefits in urban parks, we need to acknowledge that a multitude of additional 
Fig. 3. Malmö heat map based on residual from regression excluding only distance to closest park and park size from the regression. Red (blue) areas indicate that properties in that region typically sell at a relatively higher (lower) price. The legend indicates the magnitude of the difference. Taking the exponential of these values we get the percentage relative difference in selling price for the different areas.

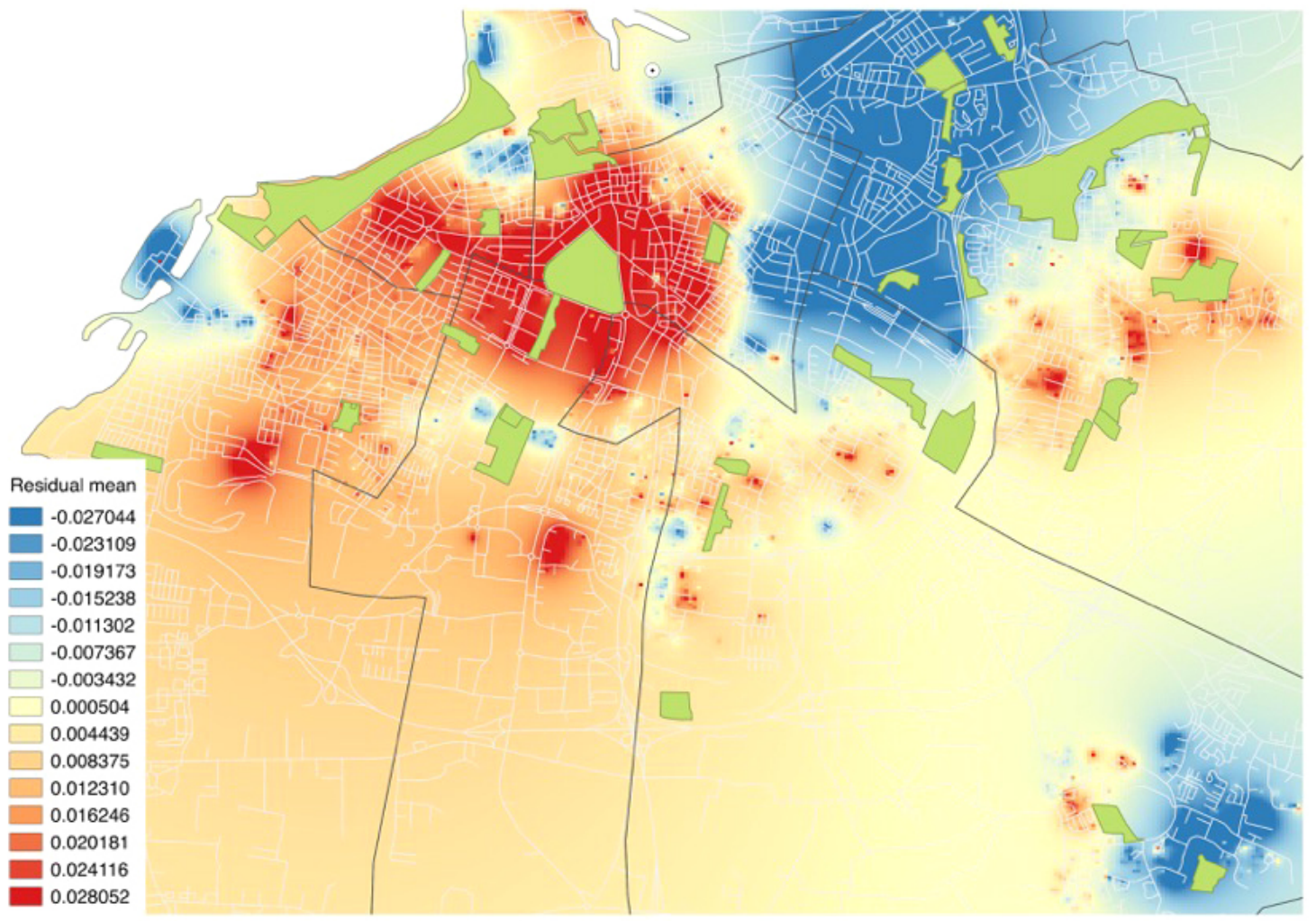

variables are needed to fulfill the purpose of the different dimensions, e.g., diversity of animal and plant species, access to shade and sun, number of bushes, ponds, benches, presence of a soccer field, access to restrooms, etc. There is thus a need to develop methods and tools for translating the different qualitative variables into quantitative measures, as well as assessing just how large the urban park needs to be to, e.g., to have people perceive the area as silent and calm (a prerequisite for the environmental dimension "Serene"). Although several studies indirectly imply the need for space to accomplish certain benefits, they do not provide quantitative measures of the required space to provide the benefits of interest (see, e.g., Stockholms Regionplane-och trafikkontor 2001, van Herzele 2005). Furthermore, because urban parks do not function in isolation, it is necessary to also take the surrounding land use configuration into account, in the process of assessing appropriate park size, because land uses in urban green areas could synergistically interact to support, e.g., biodiversity when clustered together in different combinations (Colding 2007).

\section{Accounting for distance to urban parks}

The Euclidean (straight line) distance to a park, which is the other park-related parameter in our HPM (the first one being size or park area [see Fig. 3]), is not the straightforward parameter it may seem like at first glance. What we are really interested in, in a sustainable planning and design context, is the accessibility of the park. In this context street morphology and human cognition are parameters that are claimed to provide the basis for peoples' accessibility (see, e.g., Oh and Jeong 2007). However, because straight-line distance is not sensitive to these parameters, we need to look for alternatives. Apart from the straight-line distance, there is also walking distance (in the pedestrian network) and (directional) axial line step distance. The straight-line distance and the walking distance are both Euclidean measures in meters (Lee and Moudon 2006). The axial line can be regarded as a kind of people-based distance measure, because it is adding data about the cognitive environment into the analytical framework (Hillier 2003), which is claimed to be one of the major deficiencies in contemporary accessibility research (Kwan 2000). Factors that may contribute to shaping the cognitive environment are, e.g., public availability, if the park is fenced or not, and the use of entrance fees, potentially excluding some population groups (Low 2003). Also, urban parks may be differently perceived and used by population subgroups, e.g., according to gender, age group, or cultural background. Thus, using axial line step distance instead of Euclidean distance may prove useful in explaining, e.g., surprisingly low values of properties in connection to geographically close parks, as well as contributing to the provisioning of guidelines in a sustainable urban planning and design context. 
Accounting for unperceived benefits from urban parks

Another limitation of the HPM is that it, unsurprisingly, only captures the perceived benefits from urban parks, in economic terms the perceived direct and indirect use values. A direct use value of a park could be the park's function as a meeting place and an indirect use value could be valuing the view over the park through the window of your home (Ståhle 2006). If the benefits that people do perceive and thus include in the HPM covered all the benefits potentially generated within the park, a HPM would be sufficient when valuing the park in the context of making all the aggregated benefits of that park visible. However, this is not the case. Urban ecosystem services such as carbon storage, water infiltration, and habitat provisioning for key species, such as pollinators and seed dispersers (see, e.g., Lundberg and Moberg 2003, Marcus et al. 2014), also benefit the urban population in a multitude of ways (Gómez-Baggethun et al. 2013), but are most likely not captured in the HPM, judging from what type of benefits that people in general perceive and prefer in an urban park (see, e.g., Ståhle 2006, Grahn and Stigsdotter 2010). Also, peoples' inability to perceive benefits that are generated inside the park but are enjoyed somewhere else is problematic in a planning and design context (Raudsepp-Hearne and Peterson 2016). A third ecosystem services type where people may have difficulty linking the service and the benefit is when the benefit is enjoyed as an overall general improvement in some parameter not directly connected to the geographical location of the park, e.g., the benefit of reduced climate change effects through carbon storage in park vegetation and soil. To get at these types of shortcomings, in an urban planning and design context, there is a need to merge ecological and socioeconomic aspects of who is benefiting from ecosystem services and where (see, e.g., Polasky et al. 2005, TEEB 2010) and to apply valuation approaches capable of embracing and disaggregating benefits other than just those perceived by people living next to the urban park and where the benefits are strictly enjoyed within the boundaries of the park. Valuation approaches that may serve this purpose better than the HPM are, e.g., approaches focusing on land use planning and design from the start by, e.g., applying an ecosystem service approach within the context of multifunctionality and spatial specificity (see, e.g., Tallis and Polasky 2009, Bateman et al. 2013, Ma et al. 2016).

\section{CONCLUSIONS}

Our results show that an HPM would benefit from using both a lagged dependent and error specification in combination with the spatial fixed effects when accounting for autocorrelation, to more accurately predict the relation between distance to parks and property values. When correcting more effectively for autocorrelation, the HPM still show that people have a willingness to pay for living next to a park and hence the method delivers on analyzing aggregated perceived benefits associated with urban parks, making these benefits more visible. This type of information is useful for promoting urban parks more effectively as a part of public policy. We suggest that the results of the HPM may be even better explained by adding data about the cognitive environment into the analytical framework, by, e.g., replacing a Euclidian distance measure with an axial line step distance, i.e., focusing on accessibility. Furthermore, the heat maps, created by using the residuals retrieved from regressions of different complexities, depict the spatial differentiation of these values and may thus be useful for some planning purposes because it spatially reveals which parks are more or less attractive.
However, although our results suggest that parks indeed have a positive effect on property value and that this effect tends to increase with reduced distance to the parks, the HPM, even with the additional spatial information, provided by the heat maps, does not provide enough details about the nature of the relations between urban parks and human welfare to make the information especially useful in a sustainable planning and design context. To more effectively include the values of different health benefits generated by urban parks into urban planning and design strategies, we suggest applying alternative valuation approaches capable of disaggregating the different health benefits by including benefits irrespective of whether these benefits are enjoyed in direct relation to the park or not, or perceived by people living next to the park or not. This may be done, e.g., by combining approaches such as ecosystem services, multifunctionality, and spatial specificity (see, e.g., Bateman et al. 2013, Ma et al. 2016). In the context of broadening and operationalizing the array of health benefits generated by urban parks, we also suggest that qualitative health dimensions, as identified within the field of environmental psychology, such as "Serene," "Space," and "Nature" need to be translated into quantitative measures because, although much has been achieved in the context of promoting health in cities (see, e.g., WHO 2014), there is still a considerable lack of data on the many functions and values of ecosystems and landscapes (de Groot 2006).

Responses to this article can be read online at: http://www.ecologyandsociety.org/issues/responses. $\mathrm{php} / 9365$

\section{Acknowledgments:}

We want to thank two anonymous reviewers for valuable comments on the manuscript. This research was produced within the URBES project, kindly funded by the joint call from ERA-Net, BIODIVERSA, 2010-2011.

\section{LITERATURE CITED}

Alriksson, S., and T. Öberg. 2008. Conjoint analysis for environmental evaluation. Environmental Science and Pollution Research 15(3):244-257. http://dx.doi.org/10.1065/espr2008.02.479

Andersson, E., M. Tengö, T. McPhearson, and P. Kremer. 2015. Cultural ecosystem services as a gateway for improving urban sustainability. Ecosystem Services 12:165-168. http://dx.doi. org/10.1016/j.ecoser.2014.08.002

Andersson, R., and L. Hedman. 2016. Economic decline and residential segregation: a Swedish study with focus on Malmö. Urban Geography 37(5):748-768. http://dx.doi.org/10.1080/0272$\underline{3638.2015 .1133993}$

Annerstedt, M. 2011. Nature and public health: aspects of promotion, prevention, and intervention. Dissertation. Acta Universitatis Agriculturae Sueciae, Alnarp, Sweden.

Anselin, L. 1988. Spatial econometrics: methods and models. Springer, Dordrecht, The Netherlands. http://dx.doi. org/10.1007/978-94-015-7799-1 
Anselin, L., and D. Arribas-Bel. 2013. Spatial fixed effects and spatial dependence in a single cross-section. Papers in Regional Science 92(1):3-17. http://dx.doi.org/10.1111/j.1435-5957.2012.00480. $\underline{x}$

Anselin, L., A. K. Bera, R. Florax, and M. J. Yoon. 1996. Simple diagnostic tests for spatial dependence. Regional Science and Urban Economics 26:77-104. http://dx.doi.org/10.1016/0166-0462 (95)02111-6

Arraiz, I., D. M. Drukker, H. H. Kelejian, and I. R. Prucha. 2010. A spatial Cliff-Ord-type model with heteroskedastic innovations: small and large sample results. Journal of Regional Science 50:592-614. http://dx.doi.org/10.1111/j.1467-9787.2009.00618.x

Bateman, I. J., A. R. Harwood, G. M. Mace, R. T. Watson, D. J. Abson, B. Andrews, A. Binner, A. Crowe, B. H. Day, S. Dugdale, C. Fezzi, J. Foden, D. Hadley, R. Haines-Young, M. Hulme, A. Kontoleon, A. A. Lovett, P. Munday, U. Pascual, J. Paterson, G. Perino, A. Sen, G. Siriwardena, D. van Soest, and M. Termansen. 2013. Bringing ecosystem services into economic decisionmaking: land use in the United Kingdom. Science 341 (6141):45-50. http://dx.doi.org/10.1126/science.1234379

Bin, O., and S. Polasky. 2004. Effects of flood hazards on property values: evidence before and after hurricane Floyd. Land Economics 80:490-500. http://dx.doi.org/10.2307/3655805

Boyer, T., and S. Polasky. 2004. Valuing urban wetlands: a review of non-market valuation studies. Wetlands 24(4):744-755. http:// dx.doi.org/10.1672/0277-5212(2004)024[0744:vuwaro]2.0.co;2

Colding, C. 2007. 'Ecological land-use complementation' for building resilience in urban ecosystems. Landscape and Urban Planning 81(1-2):46-55. http://dx.doi.org/10.1016/j.

landurbplan.2006.10.016

Costanza, R., M. A. Wilson, A. Troy, A. Voinov, S. Liu, and J. D'Agostino. 2006. The value of New Jersey's ecosystem services and natural capital. Gund Institute for Ecological Economics, University of Vermont, Burlington, Vermont, USA.

de Groot, R. S. 2006. Function-analysis and valuation as a tool to assess land use conflicts in planning for sustainable, multifunctional landscapes. Landscape and Urban Planning 75:175-186. http://dx.doi.org/10.1016/j.landurbplan.2005.02.016

Drukker, D. M., P. Egger, and I. R. Prucha. 2013. On two-step estimation of a spatial autoregressive model with autoregressive disturbances and endogenous regressors. Econometric Reviews 32 (5-6):686-733. http://dx.doi.org/10.1080/07474938.2013.741020

Elmqvist, T., M. Fragkias, J. Goodness, B. Güneralp, P. J. Marcotullio, R. I. McDonald, S. Parnell, M. Schewenius, M. Sendstad, K. C. Seto, and C. Wilkinson. 2013. Global urbanization, biodiversity, and ecosystems: challenges and opportunities. A global assessment. Springer Verlag, Dordrecht, The Netherlands.

Escobedo, F. J., T. Kroeger, and J. E. Wagner. 2011. Urban forests and pollution mitigation: analyzing ecosystem services and disservices. Environmental Pollution 159(8-9):2078-2087. http:// dx.doi.org/10.1016/j.envpol.2011.01.010

Gómez-Baggethun, E., Å. Gren, D. N. Barton, J. Langemeyer, T. McPhearson, P. O'Farrell, E. Andersson, Z. Hamstead, and P.
Kremer. 2013. Urban ecosystem services. Pages 175-251 in $\mathrm{T}$. Elmqvist, M. Fragkias, J. Goodness, B. Güneralp, P. J. Marcotullio, R. I. McDonald, S. Parnell, M. Schewenius, M. Sendstad, K. C. Seto, and C. Wilkinson, editors. 2013. Urbanization, biodiversity and ecosystem services: challenges and opportunities. A global assessment. Springer Verlag, Dordrecht, The Netherlands. http://dx.doi.org/10.1007/978-94-007-7088-1 11

Grahn, P., and U. A. Stigsdotter. 2003. Landscape planning and stress. Urban Forestry and Urban Greening 2:1-18. http://dx.doi. org/10.1078/1618-8667-00019

Grahn, P., and U. K. Stigsdotter. 2010. The relation between perceived sensory dimensions of urban green space and stress restoration. Landscape and Urban Planning 94:264-275. http://dx. doi.org/10.1016/j.landurbplan.2009.10.012

Hartig, T., and P. H. Kahn Jr. 2016. Living in cities, naturally. Science 352(6288):938-940. http://dx.doi.org/10.1126/science. $\underline{\text { aaf3759 }}$

Hartig, T., R. Mitchell, S. de Vries, and H. Frumkin. 2014. Nature and health. Annual Review of Public Health 35:207-228. http://dx. doi.org/10.1146/annurev-publhealth-032013-182443

Hatton MacDonald, D., N. D. Crossman, P. Mahmoudi, D. Summers, L. O. Taylor, D. M. Summers, and P. C. Boxall. 2010. Valuing public and private green spaces. Landscape and Urban Planning 95:192-200. http://dx.doi.org/10.1016/j.landurbplan.2010.01.003

Helm, D. 2015. Natural capital: valuing our planet. Yale University Press, New Haven, Connecticut, USA.

Hillier B. 2003. The architectures of seeing and going: or, are cities shaped by bodies or minds? And is there a syntax of spatial cognition? Proceedings of the 4th International Symposium in Space Syntax, London, UK.

James, P., M. Holden, M. Lewin, L. Neilson, C. Oakley, A. Truter, and D. Wilmoth. 2013. Managing metropolises by negotiating mega-urban growth. Pages 217-232 in H. A. Mieg and K. Töpfer, editors. Institutional and social innovation for sustainable urban development. Routledge, London, UK.

Kaczynski, A. T., and K. A. Henderson. 2007. Environmental correlates of physical activity: a review of evidence about parks and recreation. Leisure Science 29(4):315-354. http://dx.doi. org/10.1080/01490400701394865

Kazmierczak, A. 2013. The contribution of local parks to neighborhood social ties. Landscape and Urban Planning 109:31-44. http://dx.doi.org/10.1016/j.landurbplan.2012.05.007

Kelejian, H. H., and I. R. Prucha. 1998. A generalized spatial two-stage least squares procedures for estimating a spatial autoregressive model with autoregressive disturbances. Journal of Real Estate Finance and Economics 17:99-121. http://dx.doi. org/10.1023/A:1007707430416

Kelejian, H. H., and I. Prucha. 1999. A generalized moments estimator for the autoregressive parameter in a spatial model. International Economic Review 40:509-533. http://dx.doi. org/10.1111/1468-2354.00027

Kolbe, J., and H. Wüstemann. 2015. Estimating the value of urban green space: a hedonic pricing analysis of the housing market in 
Cologne, Germany. SFB 649 Discussion Paper 2015-002. Humboldt-Universität zu Berlin, Germany. [online] URL: http:// edoc.hu-berlin.de/series/sfb-649-papers/2015-2/PDF/2.pdf

Kong, F., H. Yin, and N. Nakagoshi. 2007. Using GIS and landscape metrics in the hedonic price modeling of the amenity value of urban green space: a case study in Jinan City, China. Landscape and Urban Planning 79:240-252. http://dx.doi. org/10.1016/j.landurbplan.2006.02.013

Kuminoff, N. V., C. F. Parmeter, and J. C. Pope. 2010. Which hedonic models can we trust to recover the marginal willingness to pay for environmental amenities? Journal of Environmental Economics and Management 60(3):145-160. http://dx.doi. org/10.1016/j.jeem.2010.06.001

Kwan, M. 2000. Analysis of human spatial behaviour in a GIS environment: recent developments and future prospects. Journal of Geographical Systems 2:85-90. http://dx.doi.org/10.1007/ $\underline{\mathrm{s} 101090050034}$

Lee, C., and A. V. Moudon. 2006. The 3Ds + R: quantifying land use and urban form correlates of walking. Transportation Research Part D: Transport and Environment 11:204-215. http:// dx.doi.org/10.1016/j.trd.2006.02.003

Lovell, S.T., and J. R. Taylor. 2013. Supplying urban ecosystem services through multifunctional green infrastructure in the United States. Landscape Ecology 28:1447-1463. http://dx.doi. org/10.1007/s10980-013-9912-y

Low, S. 2003. Behind the gates. Routledge, London, UK.

Lundberg, J., and F. Moberg. 2003. Mobile link organisms and ecosystem functioning: implications for ecosystem resilience and management. Ecosystems 6:87-98. http://dx.doi.org/10.1007/ s10021-002-0150-4

Ma, S., J. M. Duggan, B. A. Eichelberger, B. W. McNally, J. R. Foster, E. Pepi, M. N. Conte, G. C. Daily, and G. Ziv. 2016. Valuation of ecosystem services to inform management of multiple-use landscapes. Ecosystem Services 19:6-18. http://dx. doi.org/10.1016/j.ecoser.2016.03.005

Mahan, B. L., S. Polasky, and R. M. Adams. 2000. Valuing urban wetlands: a property price approach. Land Economics 76:100-113. http://dx.doi.org/10.2307/3147260

Mahmoudi, P., D. H. MacDonald, N. D. Crossman, D. M. Summers, and J. van der Hoek. 2013. Space matters: the importance of amenity in planning metropolitan growth. Australian Journal of Agricultural and Resource Economics 57:38-59. http://dx.doi.org/10.1111/j.1467-8489.2012.00608.x

Marcus, L., M. Berghauser-Pont, and Å. Gren. 2014. Can spatial form support urban ecosystem services: developing descriptions and measures to capture the spatial demands for pollination using the framework of space syntax. A/Z ITU Journal of the Faculty of Architecture 11(2):255-270.

Martín-López B, E. Gómez-Baggethun, M. García-Llorente, and C. Montes. 2014. Trade-offs across value-domains in ecosystem service assessment. Ecological Indicators 37:220-228 http://dx. doi.org/10.1016/j.ecolind.2013.03.003

Millennium Ecosystem Assessment (MA). 2005. Ecosystems and human well-being: synthesis. Island, Washington, D.C., USA.
Mitchell, R., and F. Popham. 2008. Effect of exposure to natural environment on health inequalities. Lancet 372:1655-1660. http:// dx.doi.org/10.1016/S0140-6736(08)61689-X

Nelson, E., G. Mendoza, J. Regetz, S. Polasky, H. Tallis, D. R. Cameron, K. M. A. Chan, G. Daily, J. Goldstein, P. M. Kareiva, et al. 2009. Modeling multiple ecosystem services, biodiversity conservation, commodity production, and tradeoffs at landscape scales. Frontiers in Ecology and the Environment 7(1):4-11. http:// dx.doi.org/10.1890/080023

Nutsford, D., A. L. Pearson, S. Kingham, and F. Reitsma. 2016. Residential exposure to visible blue space (but not green space) associated with lower psychological distress in a capital city. Health and Place 39:70-78. http://dx.doi.org/10.1016/j. healthplace.2016.03.002

Oh, K., and S. Jeong. 2007. Assessing the spatial distribution of urban parks using GIS. Landscape and Urban Planning 82:25-32. http://dx.doi.org/10.1016/j.landurbplan.2007.01.014

Polasky, S., E. Nelson, E. Lonsdorf, P. Fackler, and A. Starfield. 2005. Conserving species in a working landscape: land use with biological and economic objectives. Ecological Application 15:1387-1401. http://dx.doi.org/10.1890/03-5423

Raudsepp-Hearne, C., and G. D. Peterson. 2016. Scale and ecosystem services: how do observation, management, and analysis shift with scale-lessons from Québec. Ecology and Society 21(3):16. http://dx.doi.org/10.5751/ES-08605-210316

Rosen, S. 1974. Hedonic prices and implicit markets: product differentiation in pure competition. Journal of Political Economy 82(1):34-55. http://dx.doi.org/10.1086/260169

Seto, K. C., B. Guneralp, L. R. Hutyra. 2012. Global forecasts of urban expansion to 2030 and direct impacts on biodiversity and carbon pools. Proceedings of the National Academy of Sciences of the USA 109(40):16083-16088. http://dx.doi.org/10.1073/ pnas. 1211658109

Soga, M., Y. Yamaura, T. Aikoh, Y. Shoji, T. Kubo, and K. J. Gaston. 2015. Reducing the extinction of experience: association between urban form and recreational use of public greenspace. Landscape and Urban Planning 143:69-75. http://dx.doi. org/10.1016/j.landurbplan.2015.06.003

Ståhle, A. 2006. Sociotope mapping: exploring public open space and its multiple use values in urban and landscape planning practice. Nordic Journal of Architectural Research 19(4):59-71.

Stockholms Regionplane-och trafikkontor. 2001. Upplevelsevärden. Sociala kvaliteter $i$ den regionala grönstrukturen. [Experiencing values. Social qualities in the regional green structure]. Regionplane- och trafikkontoret, Stockholms stad, Stockholm, Sweden.

Tallis, H., and S. Polasky. 2009. Mapping and valuing ecosystem services as an approach for conservation and natural-resource management. Annals of the New York Academy of Sciences 1162:265-283. http://dx.doi.org/10.1111/j.1749-6632.2009.04152. X

Taylor, A. F., and F. E. Kuo. 2009. Children with attention deficits concentrate better after walk in the park. Journal of Attention Disorders 12(5):402-409. http://dx.doi.org/10.1177/1087054708323000 
The Economics of Ecosystems and Biodiversity (TEEB). 2010. The economics of ecosystems and biodiversity. Ecological and economic foundations. UNEP/Earthprint, London, UK.

The Economics of Ecosystems and Biodiversity (TEEB). 2011. The economics of ecosystems and biodiversity. Manual for cities: ecosystem services in urban management. UNEP and the European Commission, Brussels, Belgium.

Thor, S. 2016. Malmö är ingen genomsnittsstad. Fastighetsnytt, SYD, skåne och öresundsregionen, 11 September. [online] URL: http://fastighetsnytt.se/2016/09/malmo-ar-ingen-genomsnittsstad/

Treweek, J. 1999. Ecological impact assessment. Blackwell Science Ltd. London, UK.

Tyrväinen, L. 1997. The amenity value of the urban forest: an application of the hedonic pricing method. Landscape and Urban Planning 37:211-222. http://dx.doi.org/10.1016/S0169-2046(97) $\underline{80005-9}$

Tyrväinen, L., and A. Miettinen. 2000. Property prices and urban forest amenities. Journal of Environmental Economics and Management 39:205-223. http://dx.doi.org/10.1006/jeem.1999.1097

van Herzele, A. 2005. A tree on your doorstep, a forest in your mind. Green space planning at the interplay between discourse, physical conditions, and practice. Dissertation. Wageningen University, Wageningen, The Netherlands.

White, H. 1980. A heteroskedasticity-consistent covariance matrix estimator and a direct test for heteroskedasticity. Econometrica 48(4):817-838. http://dx.doi.org/10.2307/1912934

Whyte, W. H. 2001. The social life of small urban spaces. 2001 edition. Project for Public Spaces, New York, New York, USA.

World Health Organization (WHO). 2014. Healthy cities. Healthy cities. Promoting health and equity - evidence for local policy and practice. Summary evaluation of Phase V of the WHO European Healthy Cities Network. E. de Leeuw, A. D. Tsouros, M. Dyakova, and G. Green, editors. WHO, Geneva, Switzerland. 